Publicación semestral. ISSN 2215-4906

Volumen 79 - Número 2

Enero - Junio 2020

\title{
Los conciertos de Teresa Carreño en Caracas en 1862: construcciones de género, virtuosismo y patriotismo
}

Teresa Carreño's Concerts in Caracas in 1862: Constructions of Gender, Virtuosity, and Patriotism

Laura Pita

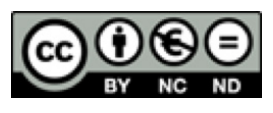

Esta obra está bajo una licencia Creative Commons Reconocimiento-No comercial-Sin Obra Derivada 
Dossier

\title{
Los conciertos de Teresa Carreño en Caracas en 1862: construcciones de género, virtuosismo y patriotismo
}

\author{
Teresa Carreño's Concerts in Caracas in 1862: \\ Constructions of Gender, Virtuosity, and Patriotism
}

\author{
Laura Pita ${ }^{1}$ \\ Columbia College \\ Estados Unidos
}

Recibido: 30 de marzo de 2019 Aprobado: 26 de julio de 2019

\section{Resumen}

En 1862, a los ocho años de edad Teresa Carreño ofreció varios conciertos privados en Caracas en los que improvisó e interpretó piezas del repertorio virtuosístico para piano. Varios miembros de los círculos musicales e intelectuales caraqueños la elogiaron ampliamente en la prensa por su habilidad musical. No obstante, la recepción de estos conciertos reflejaba entre líneas las tensiones y paradojas que se dieron en la cultura musical caraqueña entre las prácticas y valores que modelaban la vida de conciertos y la cultura de salón en Caracas, los estereotipos de género dominantes y las aspiraciones de progreso cultural que abogaba la élite política e intelectual. El presente estudio discute la recepción de los conciertos de Carreño en el contexto del entramado cultural del siglo XIX, atendiendo la forma en que estos problematizaron las convenciones de género y los valores sociales y estéticos que modelaron la producción y recepción de la música en Caracas, y cómo sirvieron para articular las aspiraciones culturales de la naciente nación venezolana.

Palabras clave: siglo XIX; conciertos; virtuosismo pianístico; música de salón; educación musical para niñas

1 Profesora Adjunta en Columbia College (Jefferson City, Missouri, Estados Unidos). Doctora en Musicología (Doctor of Philosophy, Musicology) por la University of Kentucky. Correo electrónico: Impp47@gmail.com 
Los conciertos de Teresa Carreño en Caracas en 1862: construcciones

\begin{abstract}
In 1862, eight-year-old Teresa Carreño offered several private concerts in Caracas in which she improvised and performed pieces of the virtuosic repertory for piano. Several members of the musical and intellectual circles of Caracas praised her widely in the press for her musical abilities. However, at a deeper level, the reception of these concerts reflects the tensions and paradoxes that occurred in Caracas' musical culture between the practices and values that shaped concert life and salon culture, prevalent gender stereotypes, and the aspirations of cultural progress of the educated elite. The present study discusses the reception of Carreño's concerts in the context of the cultural fabric of the 19th century, regarding the way in which they problematized the conventions of gender and the social and aesthetic values that shaped the production and reception of music in Caracas, and how they served to articulate the cultural aspirations of recently founded Venezuelan nation.
\end{abstract}

Keywords: nineteenth century; concerts; piano virtuosity; salon music; music education for girls 


\section{Introducción}

En mayo de 1862, dos meses antes de la partida de Teresa Carreño y su familia a los Estados Unidos, Felipe Larrazábal, prominente letrado y músico caraqueño, escribió un extenso comentario en la prensa local en el que expresaba sus impresiones sobre su "virtuosa compatriota"2.

Al cabo de un siglo, y no en el viejo mundo, sino en el continente de Colon, en la América del Sur, á cuya zona emigran las ciencias y las artes, y donde el cielo sereno y puro, engrandece los talentos; aquí digo, llamó Dios á la vida al sucesor y al émulo digno de MOZART. Es una joven, de Carácas. ... Un siglo media entre Mozart y la perla caraqueña; un siglo lleno de adelantos, de invenciones, de gusto y de ciencia. ¡Cuán grandes no son los progresos que en tan largo espacio de tiempo se han realizado! (Larrazábal, 1862, en Scrapbook I, p. 1)33.

Una mezcla de reverencia, orgullo patriótico y confianza en un futuro de avance cultural para Venezuela emerge del texto de Larrazábal. Similares observaciones fueron consignadas en otros artículos de periódico escritos por destacados intelectuales venezolanos. Entre estos figuran Cecilio Acosta (1862) y Jesús María Sistiaga (1862), quienes al igual que Larrazábal asistieron a los conciertos que Manuel Antonio Carreño organizó a mediados de 1862 a fin de presentar a su hija Teresa a la élite cultural de Caracas, y a la vez anunciar el viaje que la familia haría próximamente a Nueva York, La Habana, París y Londres4.

Para este momento, Teresa tenía tan solo ocho años de edad; sin embargo, ya demostraba un dominio considerable del repertorio virtuosístico para piano. Los artículos de Larrazábal, Acosta y Sistiaga abundan en descripciones sobre la habilidad de la niña para improvisar y para interpretar con fluidez piezas de considerable dificultad técnica. Estos escritos han sobrevivido en un álbum preparado por su padre, en cuyo lomo se lee la dedicatoria "Al genio" en letras doradas (Scrapbook I, 1862-1868), el cual preserva además numerosos artículos de prensa sobre los conciertos que Teresa ofreció subsecuentemente en Estados Unidos y Cuba durante su etapa de niña prodigio. La fuente forma parte de la colección Teresa Carreño Papers, actualmente en los fondos de Archives and Special Collections Library en el

2 Teresa Carreño (n. Caracas, 1853; m. Nueva York, 1917). Felipe Larrazábal (n. Caracas, 1816; m. 1873, altamar, cerca de la costa atlántica europea).

3 En esta y las restantes citas de fuentes primarias se ha preservado la ortografía y sintaxis original.

Cecilio Acosta (n. 1818, San Diego de los Altos, Venezuela, 1818; m. Caracas,1881). Jesús María Sistiaga (n. Caracas, 1823; m. Caracas, 1889). Manuel Antonio Carreño (n. Caracas, 1813; m. París, 1874).

ESCENA. Revista de las artes, 2020, Vol. 79, Núm. 2 (enero-junio), pp. 148-173 
Vassar College en Poughkeepsie, Nueva York. La colección resguarda además un grupo de partituras manuscritas consistente en una serie de quince pequeñas piezas de baile. Estas incluyen valses, polcas, mazurcas, y danzas atribuidas a Teresa Carreño y cuya fecha de copia indica que fueron compuestas cuando la familia aún vivía en Venezuela (Composiciones, 1860-1861) ${ }^{5}$. Estas piezas reflejan una notable familiaridad por parte de la joven pianista con las convenciones estilísticas del repertorio de salón que estuvo en boga en Caracas a mediados del siglo XIX (Pita, 2019).

Teresa Carreño creció en el seno de una familia de músicos notables, quienes desde 1750 y por casi un siglo habían estado a cargo de la organización de la capilla musical de la Catedral de Caracas, entonces el centro musical de mayor importancia en la ciudad. Entre estos destaca su abuelo, Cayetano Carreño, quien ocupó el cargo de maestro de capilla desde 1796 hasta 1836, desarrollando además una importante actividad como compositor $^{6}$. Los seis hijos varones de Cayetano Carreño que alcanzaron la edad adulta, incluyendo Manuel Antonio, recibieron educación musical y se desempeñaron eventualmente como cantores, organistas y maestros de capilla. Luego de los cambios sociales ocurridos en Venezuela como consecuencia del proceso independentista, los hermanos Carreño dejaron la Catedral, logrando acceder a las esferas intelectuales y políticas, en las cuales también marcaron impronta. En particular, Manuel Antonio Carreño se convirtió en una referencia cultural de relevancia en el mundo hispanoamericano a través de su famoso Manual de urbanidad y buenas costumbres, publicado en Caracas en 1853. No obstante, sus múltiples ocupaciones como intelectual y político, se ocupó de brindarle una esmerada educación musical a su hija, además de organizar sus primeras presentaciones en Caracas.

Aunque los conciertos de Teresa Carreño en Caracas fueron de caracter privado, es evidente que fueron percibidos como eventos de interés público y, como tal, fueron objeto de atención en la prensa. Los comentarios de Larrazábal (1862), Acosta (1862) y Sistiaga (1862) demuestran que Teresa Carreño comenzó a ser considerada un ícono cultural en Venezuela incluso antes de su debut público en el Irving Hall de Nueva York en Noviembre de 1862, el cual dio paso a su exitosa e influyente carrera como pianista virtuosa que se extendería por más de cinco décadas en las que ofreció recitales y conciertos en Venezuela, las Antillas del Caribe, México, Norteamérica, Europa, Suráfrica, Australia, y Nueva Zelanda. Su precocidad musical fue interpretada por sus compatriotas como símbolo del potencial de la

${ }^{5}$ Las piezas fueron copiadas por Manuel Antonio Carreño, quien atribuyó la autoría de estas a su hija al titular dicha colección como Composiciones de María Teresa Carreño. Las piezas fueron publicadas en T. Carreño (2008).

${ }^{6}$ Cayetano Carreno, n. Caracas, 1774; m. Caracas 1836. 
naciente república de alcanzar un desarrollo cultural significativo a pesar de las dificultades que enfrentaba la sociedad venezolana a causa de la Guerra Federal, en curso desde 1859.

El estudio de la recepción de los conciertos de Teresa Carreño en Caracas resulta especialmente provechoso, pues permite iluminar aspectos poco conocidos de su actividad musical temprana, además de ofrecer un caso relevante para el estudio de la cultura musical que se desarrolló en Caracas a mediados del siglo XIX, y de sus posibles conexiones con las esferas de lo social y lo político. Los artículos de Larrazábal (1862), Sistiaga (1862), y Acosta (1862) no solo dan cuenta de los extraordinarios adelantos musicales de la niña, sino que además su gran densidad filosófica muestra, entre líneas, las tensiones y paradojas que se dieron en el seno de la cultura musical de Caracas. Específicamente, estos escritos reflejan la existencia de una dinámica problemática entre las prácticas y valores que modelaban la vida de conciertos y la cultura de salón en Caracas, los estereotipos de género dominantes y las aspiraciones de progreso cultural abogada por la élite política e intelectual. Por una parte, el alto nivel de competencia musical de Teresa Carreño estaba en franca contradicción con los ideales de domesticidad femenina y las prescripciones sociales que limitaban la calidad de la educación que debían recibir las jóvenes, y el tipo de música que debían cultivar. Por otra parte, la recepción de los conciertos de Teresa Carreño se estuvo enmarcada en la ansiedad que la Guerra Federal generó entre los miembros de la élite cultural venezolana. Después de casi tres décadas de relativa estabilidad política, los profundos conflictos sociales que no habían logrado resolverse con la fundación de la República en 1830 terminaron llevando al país a una lucha encarnizada. La toma militar del gobierno por parte del expresidente y héroe independentista José Antonio Páez en septiembre de 1861, en principio destinada a tomar el control militar de la situación, fue interpretada por varios sectores caraqueños como una seria amenaza a la racionalidad, y por ende al progreso social y cultural de la nación.

El presente estudio explora la recepción y significado cultural de los conciertos de Teresa Carreño en base a los artículos de Larrazábal (1862), Acosta (1862), y Sistiaga (1862). Estos escritos son examinados dentro del entramado cultural de la Caracas de los dos primeros tercios del siglo XIX, atendiendo primero a cómo estos conciertos problematizaron las convenciones de género y los valores sociales y estéticos que configuraron la producción y percepción de la música en Caracas tanto en la esfera pública como en los círculos privados, y segundo a cómo estos conciertos sirvieron para articular las aspiraciones culturales de la élite caraqueña. 
Los conciertos de Teresa Carreño en Caracas en 1862: construcciones

Figura 1. Teresa Carreño a los nueve años de edad

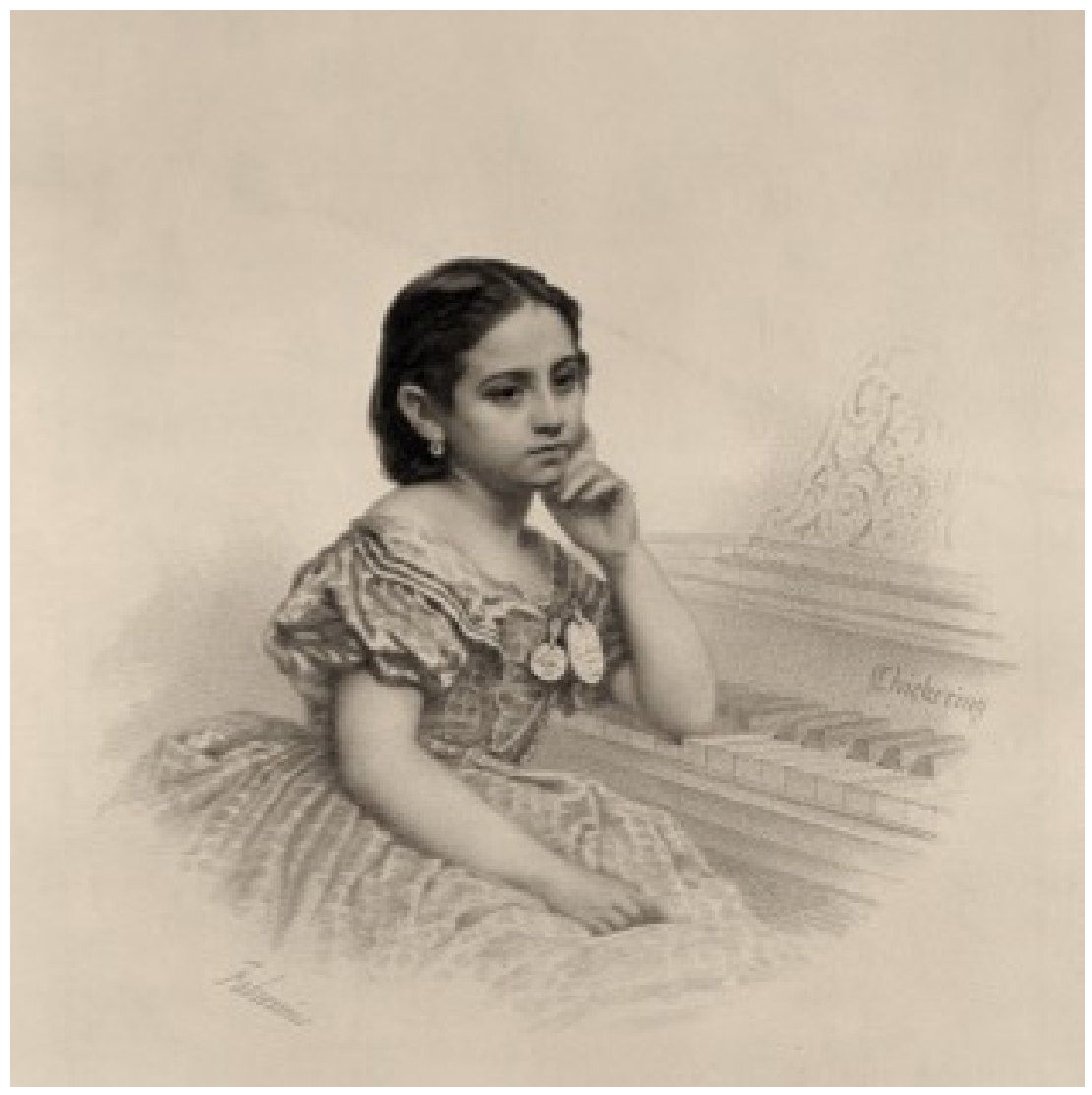

Fuente: Detalle de litografía de Dominique C. Fabronius, (1863).

\section{Inicios de la vida de conciertos en Caracas: permeabilidad entre lo privado y lo público}

A partir del establecimiento de la imprenta y la creación de la Gazeta de Caracas en 1808 comienza a formarse una esfera de opinión pública. Esta fue crucial en la discusión y propagación de las ideas independentistas que dieron lugar a la Declaración de la Independencia en 1811 y a la fundación de la República en 1830. Paralelamente, y como correlato del proceso de establecimiento de la esfera pública, se fue conformando una esfera pública de la vida musical, la cual cristalizó en la creación de la Sociedad filarmónica de Caracas. A partir de 1831, dicha institución ofrecía series de conciertos por subscripción y programas de educación musical con los que se aspiraba a fortalecer el cultivo de la música de cámara y sinfónica. Los círculos musicales que dieron vida a este proyecto percibían que estos géneros no solo poseían una superioridad estética, sino además moral, en vista 
de los beneficios sociales que, se pensaba, aportarían a la naciente república. Un panfleto publicado en 1831 anunciando el prospecto de esta Sociedad Filarmónica afirmaba:

la música ... con el mágico influjo de la armonía, dulcifica las asperezas de la vida, corrige la ferocidad de las costumbres ... aviva y aún hace nacer hermosos y grandes sentimientos; y sus progresos van siempre acompañados de la idea de la civilización del pueblo que los consigue (Bello, Isasa, Figueroa y Peña, 1831/2001, p. 139).

Otras iniciativas similares se fueron dando en los años subsiguientes. Entre estas destaca la creación de una escuela de música en 1834 patrocinada por la Sociedad Económica de Amigos del País, la cual estaba dirigida a formar instrumentistas para que participasen en una sociedad filarmónica adscrita a esa escuela (Rodríguez, 1999). Estos esfuerzos de institucionalización de la vida musical se inscribían en el marco del ideal republicano trazado por la élite educada, el cual estimulaba la educación de los ciudadanos como vía para procurar el progreso social y el reconocimiento de Venezuela por parte de otras naciones como lugar civilizado (Alcibíades, 2004). Interesaba demostrar que Venezuela era capaz de gestionarse a sí misma como nación independiente

Musicalmente, el establecimiento de sociedades animadas al cultivo de la música instrumental tuvo antecedentes en las así llamadas "academias filarmónicas" o "tertulias musicales". Estas, se habían venido formando desde las últimas décadas del siglo XVIII entre pequeños grupos de aficionados, influenciados por la filosofía, los gustos musicales y las prácticas de sociabilidad propias de la llustración (Pita, 2019). La poca documentación que ha sobrevivido concerniente a esta práctica en Caracas indica que, en principio, las academias y tertulias musicales consistieron en reuniones organizadas en espacios residenciales, las cuales fueron patrocinadas por miembros de la clase alta criolla, en las que participaban también músicos de la clase de los artesanos y que tomaron la forma de conciertos privados en los que se interpretaban piezas del repertorio de cámara y sinfónico, con gran preferencia por Haydn y otros compositores del clásico temprano (Isnardi, 1811). Es posible que la discusión sobre las aspectos formales o filosóficos de la música haya tenido también lugar en estas reuniones. Muchos de estos aspectos coinciden, especialmente en lo referente al repertorio y al formato de reunión privada, con las academias que el aficionado y autor ilustrado

7 La documentación concerniente a los dos primeros tercios del siglo XIX refleja que los músicos pertenecientes a las élites educadas eran considerados aficionados. El término refería, no al nivel de habilidad musical, ya que algunos aficionados llegaron a tener una educación musical bastante sólida, llegando a ser compositores y ejecutantes solventes, sino a su nivel social, el cual estaba por encima del de la clase asalariada. Entre ellos había abogados, médicos, militares, propietarios de haciendas y funcionarios del alto rango político (Pita, 2019).

ESCENA. Revista de las artes, 2020, Vol. 79, Núm. 2 (enero-junio), pp. 148-173 
español Tomás de Iriarte (1779) caracteriza en su famoso poema La música. Existe evidencia de que Iriarte fue conocido por los músicos activos en Caracas en los albores del siglo XIX (Quintana, 2009). No se descarta, pues, que Iriarte haya sido una referencia en la adopción de esta práctica musical.

El hecho que las academias filarmónicas y tertulias musicales se desarrollaron primariamente en los espacios residenciales ha dificultado enormemente la posibilidad de documentarlas, por lo que el tema ha estado sujeto a las más diversas interpretaciones en la historiografía musical venezolana. Sin embargo, más allá de estas dificultades, parece claro que desde las últimas décadas de la Colonia se fue formando en Caracas una cultura avocada a la apreciación de la música instrumental; esto es, la música "sublime", o "seria" y "profunda", como se le solía referir, la cual representaba en el ámbito musical el paradigma más elevado de progreso cultural (Carreño, 1853/1863). La cultura de la "música seria" estableció, pues, jerarquías y valores sociales y estéticos que estuvieron alineados con el pensamiento ilustrado y sus ideales civilizatorios.

Debido a la situación de dificultad económica y política que heredó Venezuela una vez finalizada la Guerra de Independencia, las aspiraciones de los aficionados y otros miembros de la elite de establecer intérpretes locales y un público apreciativo de la música filarmónica fueron truncadas, no pudiendo estas instituciones permanecer más allá de mediados de la década de 1840. No sería sino hasta el último tercio del siglo y bajo otras circunstancias cuando estos planes tratarían de ser llevados a cabo de nuevo (Rodríguez, 1999). No obstante, el cultivo serio de la música instrumental no desapareció. Este continuó en los espacios privados estableciendo una línea de continuidad que de una manera más o menos consistente se mantuvo durante al menos los dos primeros tercios del siglo XIX. La historiografía temprana en Venezuela refiere la existencia a mediados de siglo de varios grupos privados bajo el patrocinio de aficionados, los cuales se reunían con regularidad para ejecutar música clásica de cámara, como en el caso del círculo de Fermín de Tovar (De la Plaza, 1883/1977) y del de José Lorenzo Montero (Suárez, 1909/1999). Otros grupos, como el de Eduardo Calcaño daban también cabida a la lectura de poesía y la interpretación de piezas vocales (Suárez, 1909/1999). En cada caso, los asistentes eran miembros de la intelectualidad caraqueña, es decir, letrados y aficionados. Algunos músicos profesionales también participaban, especialmente aquellos que gozaban de mayor respetabilidad, como fue el caso del pianista alemán establecido en Caracas, Julio Hohené (De la Plaza, 1883/1977).

Cuando a mediados de la década de 1850 las compañías de ópera itinerantes y también algunos virtuosos comenzaron a visitar Caracas con regularidad, los aficionados y músicos profesionales relacionados a estos grupos privados les brindaron apoyo, según refleja la prensa (Pita, 2019). Con frecuencia participaron de manera voluntaria en conciertos 
de música vocal e instrumental a beneficio de los músicos itinerantes, generalmente tocando arreglos para ensamble de instrumentos de selecciones de ópera. Intelectuales amantes de la música como Mario de Briceño utilizaban sus escritos de prensa para incentivar el gusto de la audiencia por la música instrumental. A propósito de un concierto público a beneficio de la soprano Cecilia Saemann, en el cual también participaron el clarinetista aficionado Miguel Carmona y el profesor Julio Hohené, Briceño congratuló a los participantes por su nivel artístico y poder de convocatoria, advirtiendo que

En nuestra sociedad ... no á todos es dado atraer a un concierto concurrencia. Es preciso que las partes vocales e instrumental tengan de extraordinario alguna cosa, para que la multitud se anime, se excite y se resuelva a oír música abstracta (Briceño, 1856, p. 3).

Los eventos políticos de la Revolución de marzo de 1858, en la que resultó derrocado el gobierno de José Tadeo Monagas, y el estallido de la Guerra Federal en febrero de 1859, llevaron de nuevo al decaimiento de la vida pública de conciertos que apenas había comenzado a resurgir. Una vez más, el cultivo de la música instrumental tomaba refugio en los círculos privados, ahora absorbiendo también el gusto por las fantasías operáticas y el estilo virtuoso, como se evidenciará en los conciertos de Teresa Carreño de 1862. Es posible que para esta época el cultivo de la música instrumental dentro de los círculos privados de aficionados hubiese ya comenzado a recibir el creciente influjo de la cultura de salón, la cual se alojaba también en los espacios residenciales. Desde mediados de la década de 1840, la prensa de Caracas reflejó el creciente mercado de modas, libros, partituras, y pianos importados de Europa, especialmente de París. Ello, aunado al anhelo reformista de las élites ilustradas que deseaban hacer de esta ciudad un lugar moderno y civilizado, coadyuvó a modelar una cultura urbana, la cual favorecía las actividades recreativas de sociabilidad, tales como bailes o saraos, fiestas o soirées, y tertulias recreativas, en las que la conversación casual se combinaba con música, juegos, y otros pasatiempos (Alcibíades, 2004; Sans, 2016).

Estas prácticas culturales se dieron no solo en el grupo pequeño de familias que habían sido tradicionalmente pudientes, sino que se extendieron también a los segmentos de la clase media que tenían ahora mayor acceso a la educación y que aspiraban al ascenso social. A diferencia de las reuniones elitistas y académicas organizadas por la intelectualidad caraqueña, la cultura de salón que tomaba lugar en el modesto salón republicano de mediados de siglo dio mayor espacio a las mujeres, las cuales exhibían sus trajes à la mode y tocaban el piano, cantaban, o recitaban poesías (Alcibíades, 2004). Participar en estas reuniones se convirtió en símbolo de prestigio social. En particular, se puede afirmar que poseer un piano y la habilidad para tocarlo representaba, para usar el término de Pierre Bourdieu (1984), un "capital cultural", pues demostraba solvencia 
económica, además de educación e interés por estar al corriente con los productos culturales y las costumbres de Europa ${ }^{8}$.

Ya para 1853, la cultura de salón estaba lo suficientemente diseminada en Caracas como para que Manuel Antonio Carreño considerara incluir en su Manual de urbanidad prescripciones para establecer límites claros entre la sociabilidad de salón y las prácticas dirigidas al cultivo de la "música seria". A este respecto, observó:

La persona que cante o toque en una reunión, deberá adaptar sus piezas á la naturaleza del auditorio. La música seria y profunda es tan solo propia para los círculos de aficionados; así como la música brillante y alegre, es la única que agrada entre las personas que no poseen los conocimientos necesarios para degustar de lo mas sublime y recóndito del arte. Y es de advertirse también que, en uno y otro caso, cuando la reunión no es exclusivamente filarmónica, sino que tiene además por objeto otros entretenimientos, las piezas que se canten ó se toquen deben ser siempre cortas, á fin de que no lleguen nunca á fastidiar al auditorio (Carreño, 1853/1863, p. 279)

De este modo, Manuel Antonio Carreño diferenciaba entre prácticas recreativas, en las que tocar o cantar piezas cortas, "brillantes y alegres" era parte del repertorio de buenos modales con el cual se agradaba a los participantes, y las reuniones filarmónicas, las cuales requerían cierto nivel de educación musical a fin de poder entender y apreciar el valor artístico de la música "seria y profunda". Del texto se desprende además que cada uno de estos contextos estaba representado por un repertorio específico, el cual, o bien cumplía un rol funcional, como en el caso de las reuniones recreativas, o bien, por el contrario, era objeto de apreciación por su valor intrínseco, como en caso de las reuniones filarmónicas cuyo propósito era artístico. Es de suponer que Carreño tenía un interés personal en preservar la cultura de la música instrumental pues él era un miembro activo de las reuniones filarmónicas. Teresa Carreño durante su época adulta refería que, en su hogar paterno en Caracas, se solían congregar los músicos más distinguidos de la ciudad, sirviendo este de centro de reuniones musicales (Carreño, 1917).

\section{La cultura de salón y la educación musical femenina}

Sería erróneo suponer que las inclinaciones de Manuel Antonio Carreño por la cultura filarmónica le hubiesen llevado a mirar con desprecio el uso funcional de la música en las reuniones de tipo recreativo. Muy por el contrario, la sociabilidad de salón tuvo en Carreño

8 Bourdieu (1984) entiende por "capital cultural" la manera en que algunos grupos sociales usan la cultura para reafirmar su posición social y excluir otros grupos, para así garantizar la perpetuación de su estatus en las generaciones subsiguientes (p. 562).

ESCENA. Revista de las artes, 2020, Vol. 79, Núm. 2 (enero-junio), pp. 148-173 
uno de sus mayores voceros. A pesar del tono prescriptivo y puntilloso del Manual de urbanidad, Carreño ofrecía una visión considerablemente moderna y afable de la vida social. Este daba importancia a la sociabilidad y a la educación como vías para combatir los vicios que resultaban de la ignorancia, y a la vez facilitar la formación del tejido social que daría lugar a las transacciones que eran necesarias para progreso de la nación. Una buena parte del libro está dedicada además a establecer normas de comportamiento para actividades recreativas tales como tertulias, bailes, banquetes y visitas.

Carreño definía el salón como "el punto general de recibo" de la casa y "teatro de toda especie de sociedad” (Carreño, 1853/1863, p. 77). Así pues, el salón funcionaba como el espacio social por excelencia, una esfera en la que los individuos interactuaban articulando experiencias y sentimientos colectivos. Esta noción de "sociedad" que Carreño relaciona con el salón corresponde a lo que el sociólogo Lii (1998) ha identificado como "la esfera social". De acuerdo con Lii, la esfera social representa un espacio común, el cual puede ser real o metafórico, y que sirve de contexto a los miembros de la sociedad, más allá del círculo íntimo de la familia y los amigos cercanos, para interactuar y crear un ámbito común de experiencias y relaciones éticas sobre las que descansa la vida pública (pp. 116-117).

Si tal como se desprende del Manual de Carreño, el salón funcionaba como una esfera social, sería entonces inexacto considerar las prácticas de salón como parte del ámbito privado. A pesar de estar ubicado dentro del hogar, el salón servía más bien de contexto intermedio entre la esfera pública y la privacidad familiar. El diseño básico de la arquitectura residencial urbana de la época refleja esta ambigüedad. Las casas de los segmentos pudientes tenían generalmente las habitaciones dispuestas de manera tal que se establecía una relación de continuidad, y no de dicotomía, entre lo público y lo privado. El salón estaba al frente, y tenía amplios ventanales hacia la calle, de modo que las actividades que se realizaban allí eran visibles al exterior (Gasparini, 1962). Una serie de prescripciones sociales regían las horas y las ocasiones en que el salón se debía usar, en las que los ventanales se debían abrir, o en las que se podía tocar el piano (Carreño, 1853/1863). En las habitaciones intermedias, generalmente el comedor, un salón más pequeño, y el gabinete o cuarto de estudio, se podía recibir invitados de mayor confianza. Estas estaban ubicadas alrededor de un patio interno y conectadas por un corredor. Más al fondo se ubicaban los dormitorios, cuyo acceso estaba restringido a la familia y el personal de servicio (Gasparini, 1962).

A pesar de que Carreño suscribía el rol que el discurso republicano le había dado a la mujer como pilar de la vida doméstica, y como esposa y madre de los futuros ciudadanos, este alentaba al mismo tiempo desde su Manual de urbanidad que las mujeres participaran 
en la esfera social. Carreño concedía a la mujer un rol como modeladora de la sociedad, pues no solo como madre, sino también desde el terreno de la sociabilidad, esta debía ejercer su influjo como agente de la moral y la civilidad:

La mujer encierra en su sér todo lo lo que hai de [...] bello é interesante en la naturaleza humana; y esencialmente dispuesta á la virtud, por su conformación física y moral por la vida apacible que lleva, en su corazon encuentran digna morada las mas eminentes cualidades sociales (Carreño, 1853/1863, p. 38).

En líneas generales, el Manual de Carreño refleja una visión progresista sobre la participación de la mujer en la vida social, lo cual no era frecuente en otros textos de conducta de la época. Visiones restrictivas sobre la participación de la mujer en la sociabilidad de salón se habían hecho comunes en Caracas a través de los escritos del filósofo alemán ilustrado Joachim Campe. Su libro Eufemia ó La mujer bien instruida establecía al respecto:

La naturaleza y la sociedad han querido que el hombre fuese el protector de la muger: que ésta se uniese a él ... confesando su debilidad, mostrándole agradecimiento por los egercicios de su superioridad ... Pero ... nuestras damas ... se portan de ordinario con una conducta contraria á estos principios. ... Pretenden dar el tono, no solo en las tertulias, pues allí pudiera disimulárseles, sino en las artes, en las ciencias, y hasta en los negocios, para los cuales no tienen capacidad alguna (Campe, 1840, pp. 137-138).

Por su parte, el famoso libro Cartas sobre la educación del bello sexo, atribuido al intelectual español José Joaquín de Mora, quien habría usado el engañoso pseudónimo de "una señora americana", advertía sobre las consecuencias irreparables que aguardaban a las mujeres que se dedicaran al estudio serio de la música y a participar en reuniones musicales:

Cuando estas [las jóvenes] favorecen el estudio de la Musica ... todo el tiempo, todas las facultades, toda la atencion se aplica a este solo obgeto, y a el se sacrifican no solo los demas ramos de la Educacion intelectual, si no la enseñaza indispensable de la [educación] domestica (Cartas, 1824, pp. 67).

Y luego agrega:

Cuando una muger ha llegado a esta situacion, tiene delante de si una larga carrera de infortunios. La idea dominante de su vida, el fin único de sus esperanzas, y deseos, es la conservacion de los aplausos que su talento arranca en las tertulias, y academias ... Si llega a ser madre, o abandona enteramente sus obligaciones

9 Sobre la atribución de la autoría de Cartas sobre la educación del bello sexo a José Joaquín de Mora véase Macintyre (2010). 
sagradas, o tiene que renunciar al metodo de vida que ha seguido hasta entonces, y a la habilidad que tanto trabajo, tanto dinero, y tanto desvelo le ha costado adquirir (Cartas, 1824, pp. 68-69).

Es este punto, es conveniente distinguir entre lo que en el siglo XIX se entendía por educación necesaria y por educación ornamental. La educación necesaria era aquella indispensable para que la mujer cumpliese su rol social como educadora de sus hijos y administradora del hogar. Incluía la instrucción básica, es decir, lectura, escritura y aritmética, además de la educación moral. En contraposición, la educación ornamental era aquella que permitía agregar brillo y belleza a la vida familiar y al círculo social en el estas se desenvolverían. Esta por lo general incluía la música, el dibujo, y la pintura (Alcibíades, 2004).

La crítica de Mora estaba dirigida, pues, a desalentar el estudio avanzado de la música, pues pensaba que esta debía ser solo atendida de manera casual para que no robase tiempo a las materias que formaban parte de la educación necesaria. En realidad, una buena parte de la sociedad veía la música como una actividad apropiada y útil para las jóvenes, pues el interés en la música las alejaba del ocio, y de las ocupaciones reñidas con la moral (Alcibíades, 2004). Sin embargo, tal como refleja Mora (Cartas, 1824), dedicarse a la actividad musical se veía como algo pernicioso, pues la joven que deseara llegar a un alto nivel de maestría debía sacrificar el rol que la sociedad le designaba como pilar de la vida doméstica, sobre el cual se esperaba que construyese su felicidad. Además, el logro musical podía llevarla a asumir actitudes contrarias al ideal de modestia y recato, los cuales se veían como emblema de la virtud femenina.

Carreño no tomó posición en su Manual de urbanidad sobre el tipo de educación musical que se debía dar a las niñas. Sin embargo, advertía de manera general que aquellas actividades dirigidas a servir de ornamento debían estar aunadas a la moral:

Piensen, pues, las jóvenes que se educan, que su alma, templada por el Criador para la virtud, debe nutrirse únicamente con los conocimientos útiles que sirven á esta de precioso ornamento ... y que en las gracias, que todo pueden embellecerlo y todo pueden malograrlo, tan solo deben buscar aquellos atractivos que se hermanan bien con el pudor y la inocencia (Carreño, 1853/1863, pp. 38-39).

La línea de separación entre lo que era aceptable desde el punto de vista moral, o apropiado por razones de conveniencia, no estaba claro ni en el Manual de Carreño ni en las Cartas de Mora. En la práctica, estas líneas estuvieron sujetas a negociaciones de tipo cultural, las cuales podían incluir argumentos pedagógicos, de clase social, de utilidad pública, etc. En este sentido, llama la atención el libro de la autora francesa Natalie de Lajolais (1843), Livre des mères de famille, el cual circuló en Caracas a mediados de siglo. Este texto ofrece una línea argumentativa que defiende la posibilidad de que las jóvenes 
que mostraran un talento excepcional en algún ramo intelectual o artístico recibieran una educación especializada a fin de desarrollarse en esa área, siempre que esto fuese compatible con la clase social y el estilo de vida de su familia. En este sentido, Lajolais reinterpreta la distinción tradicional entre la educación necesaria y la educación ornamental, introduciendo la distinción entre la "instrucción elemental o esencial" y la "instrucción perfeccionada" (1843, pp. 6-7). La primera comprendía las materias que eran necesarias y debían ser impartidas para la generalidad de los estudiantes, mientras que la segunda abarcaba "todas las ciencias, la literatura y las artes," y que debía ser ofrecida.

l'instruction élémentaire ou essentielle ... et ... l'éducation perfectionnée, embrassant toutes les sciences, les lettres et les arts, doit être le partage des personnes qui ont les facultés nécessaires pour la recevoir complète, et qui peuvent en jouir sans se voir perdues, abandonnés, dans un monde à part de celui de leur parents, de leurs amis, en dehors de mours et des habitudes du rang social où elles sont nées [solo a aquellas personas que tengan las facultades necesarias para recibir [una instrucción] completa y que puedan disfrutarla sin perderse ni abandonarse en un mundo aparte del de sus padres, sus amigos, y fuera de las costumbres y los hábitos del rango social en el cual nacieron] (Lajolais, 1843, pp. 6-7).

Es difícil determinar el tipo de línea argumentativa que pudo haber empleado Manuel Antonio Carreño para justificar la educación musical intensiva que él mismo le impartió a su hija. Sin embargo, podría conjeturarse una posición similar a la de Lajolais. La evidencia documental demuestra que desde de la edad de seis años Teresa Carreño ya practicaba cuatro horas diariamente bajo la supervisión de su padre (Brower, 1913). Su rutina diaria incluía una serie de ejercicios de mecanismo diseñados por su padre, los cuales ella debía tocar en todas las tonalidades (Carreño, ca. 1859-1869). Además, entrenaba diariamente en la lectura a primera vista y la transposición (Brower, 1913). Los manuscritos musicales de esta época sugieren que también Teresa Carreño fue entrenada en la composición y la improvisación (Composiciones, 1860-1861).

\section{Los conciertos de Teresa Carreño}

Ciertamente, el haber tenido un talento excepcional le permitió a Teresa Carreño navegar a través de las convenciones de género, y acceder a un tipo de educación musical que requería un gran nivel de dedicación. Igualmente, le permitió acceder a prácticas musicales que excedían la función de ornamento que estaba culturalmente asociada con la imagen de señoritas tocando el piano en actividades recreativas de salón.

Se desconoce el número exacto de presentaciones que Teresa realizara en su época en Caracas. Las fuentes recogen impresiones de cuatro de estas, las cuales ocurrieron entre mayo y julio de 1862 (Larrazábal, 1862; Sistiaga, 1862; Acosta, 1862). Sin embargo, Acosta 
sugiere que pudieron haber sido varias más. En todo caso, tres de las presentaciones tuvieron lugar en la residencia de los Carreño y otra más en la residencia de Cecilio Acosta. Estas contaron con un programa bastante estructurado el cual ella era la única ejecutante. Entre las piezas figuraron la difícil Grande Fantaisie et Variations sur des Motifs de l'Opéra Norma de Bellini, op. 12 de Thalberg, la Variación IV del Hexameron: Grandes variations de Bravoure sur la Marche des Puritains de Bellini, S392/R131 de Herz, la Fantaisie de Lucie de Lamermoor de Donizetti, op. 8 de Émile Prudent, el Souvenir d'll Trovatore de Verdi, op. 79 de Alexandre Edouard Goria, y el Capriccio brillant en Si Menor, op. 22 de Mendelsohn, presumiblemente el arreglo para piano solo.

Las presentaciones cerraban generalmente con improvisaciones. Para ello, los miembros de la audiencia sugerían temas musicales, siguiendo las convenciones de la cultura virtuosa europea de la primera mitad del siglo XIX. Otro tipo de improvisación, por lo demás muy original, también tomo lugar en estos conciertos. Este consistía en producir temas musicales basados en argumentos dramáticos que le iba dando la audiencia. La niña improvisaba no solo la música sino además las palabras que explicaban la trama, como si se tratara de una obra teatral. Acosta lo describía de este modo:

No se puede pintar con colores apropiados lo que presenciamos como testigos en esas cuatro horas llenas de prodigio de improvisación. Cada uno le daba un motivo ó un argumento fantástico. Alguno de esos argumentos duró en la ejecución hasta tres cuartos de hora. Era cosa singular verla, después que se hacia cargo, concebir la obertura í tocarla; í ponerse después á desenvolver sin parar, todo el argumento, con tanta propiedad de expresión, con tanta alteza de conceptos, con tanta armonía imitativa, tan bien dialogado, tan animados en la acción (Acosta, 1862, en Scrapbook I, p. 11).

Es evidente que las piezas de enorme dificultad técnica que Teresa interpretaba demandaban mucha más atención que las pequeñas piezas "brillantes y ligeras" que el Manual de urbanidad (1853/1863) prescribía para las reuniones de salón (p. 279). Aunque Manuel Antonio Carreño no fue específico en cuanto al repertorio apropiado para las prácticas de salón, el contexto sugiere que se trataba posiblemente de danzas, y también del tipo de piezas llamadas "fáciles y brillantes". Estas últimas circularon a gran escala en Europa y las Américas durante el siglo XIX a través del mercado musical, y eran usadas contextos recreativos, pues a pesar de ser auditivamente llamativas, no requerían una técnica pianística avanzada (Parakilas, 2002). En contraste, el repertorio que Teresa Carreño tocaba era representativo del estilo brillante de concierto. Este se desarrolló en Europa durante la primera mitad del siglo XIX, e iba a la par de las mejoras del mecanismo del piano para la producción de sonido y la creciente necesidad de los virtuosos itinerantes de mostrar extraordinarias capacidades como ejecutantes en una escena musical que se 
había vuelto altamente competitiva (Parakilas, 2002). Estaba caracterizado por el uso abundante de ornamentos, episodios figurativos, y predilección por una articulación ligera y un sonido perlado.

Otros elementos presentes en las descripciones de Teresa Carreño sugieren de manera bastante clara que sus conciertos se adscribían a los valores de la cultura musical seria. Acosta (1862), por ejemplo, refiere que la audiencia estaba conformada por "aficionados, inteligentes, y artistas". Se trataba pues, no de personas de variado nivel educativo, como las que concurrían a las actividades recreativas de salón, si no por un círculo de entendidos en materia musical. Por otra parte, la riqueza conceptual de los comentarios de Acosta y Larrazábal, que incluían abundantes citas en latín de la poesía de Ovidio, Horacio y Dante, además de su insistencia en comparar a Teresa Carreño con Mozart, indican que la élite ilustrada de Caracas asumió que los conciertos de Teresa eran eventos artísticos de gran seriedad.

Finalmente, como ya Mario Milanca (2000) ha observado, las presentaciones de Teresa Carreño no se realizaron en el salón, sino en el gabinete, que era la habitación de la casa designada para el estudio y el trabajo intelectual. Sus conciertos estuvieron, pues, alejados de la publicidad y distracciones de la sociabilidad, las cuales eran más bien propias del salón. Esto permite conjeturar que, convencionalmente, las distintas prácticas musicales podían ser ubicadas bien en el gabinete o en el salón, dependiendo del nivel de publicidad o privacidad que cada tipo de reunión representaba, así como también del nivel de atención que la música requería por parte de los concurrentes. Así pues, actividades como las tertulias recreativas en que la música era asumida como una actividad de carácter funcional eran realizadas en el salón. En contraste, las actividades en las que la música era el centro de atención, como en el caso de las reuniones de los círculos filarmónicos o de aficionados, podían llevarse a cabo en más bien en el gabinete.

\section{Teresa Carreño y las convenciones de la cultura musical de Caracas}

En los conciertos de Teresa Carreño en Caracas hubo algunos otros aspectos que contribuyeron también a problematizar las convenciones que habían modelado hasta entonces el cultivo de la "música seria" en Caracas. El paradigma ontológico de la música virtuosa, con su énfasis en la individualidad del ejecutante difería notablemente del formato colaborativo de las reuniones filarmónicas. Las prácticas virtuosísticas, las cuales enfatizaban las habilidades técnicas del ejecutante, su capacidad para crear efectos sonoros, para ornamentar, improvisar, y sobre todo para conectarse con la audiencia y conmoverla, contrastaban enormemente con el paradigma de la música de cámara y sinfónica, el cual enfatizaba el texto musical y la interpretación de los aspectos 
ideales, formales o expresivos, del texto musical, a fin de reproducir de manera fidedigna la concepción original del compositor.

Durante el siglo XIX, cada uno de estos repertorios representaba un modo distinto de concebir la música desde el punto de vista ontológico. En el paradigma representado por los géneros sinfónicos y de cámara, la música era concebida primariamente como una entidad ideal, una obra artística cuya existencia antecedía cualquier posibilidad de ser ejecutada. Por otra parte, en el paradigma virtuoso, la música era entendida primariamente como ejecución; era el proceso de producción del sonido a través de la agencia del ejecutante lo que determinaba el hecho musical. David Ferris (2003) ha propuesto el uso de los términos dicotómicos "música del ejecutante" (performer's music) y "música del compositor" (composer's music) para conceptualizar la diferencia entre estos dos modelos (pp. 354-355). Tanto la improvisación como el repertorio de fantasías virtuosas, las cuales convencionalmente daban gran libertad al ejecutante para recrear el texto escrito, pertenecen al tipo de la "música del ejecutante". Pero, como el mismo Ferris observa, las diferencias entre estas dos concepciones de la música no siempre pueden ser establecidas de manera inequívoca, por los que los géneros y prácticas musicales basadas en uno u otro modelo tienden a crear contradicciones a distintos niveles.

Es reveladora la atención que la cultura del virtuosismo musical decimonónico confirió a los aspectos visuales de la ejecución. En referencia a este punto, Richard Leppert (2002) ha señalado como elemento característico de la recepción de la música virtuosa instrumental, que tanto la expresión facial como la gestualidad del ejecutante coadyuvaban en el proceso de percepción del hecho musical, generando una serie de simbolismos que conferían significado concreto a la música. Dicho de otro modo, el cuerpo se convertía en parte significante del espectáculo musical (pp. 203-204). En contraste, esta relación entre la música y el cuerpo es notoriamente problemática en el modelo de la "música del compositor," donde los aspectos corporales y visuales de la ejecución tienden a minimizarse, puesto que vulneraban la autonomía de la obra como una entidad ideal. Este aspecto es abordado por Carl Dahlhaus (1989) quien, a propósito del cultivo serio de la música en Europa durante el siglo XIX, sostiene que los defensores de la función edificante del arte y de la autonomía de la obra desarrollaron modos de percepción en la que se aspiraba a una contemplación estética y desinteresada de la música.

Ciertamente, el problema del cuerpo es crucial para comprender los comentarios poco convencionales que generaron los conciertos de Teresa Carreño. La evidente disparidad que existía entre sus habilidades de ejecutante avanzada y su diminuto cuerpo debió haber suscitado una perplejidad tal entre los que asistían a sus presentaciones que la posibilidad para estos de tener una experiencia desencarnada y abstracta de la interpretación musical de Teresa debió haber sido prácticamente inviable. Los artículos publicados en la prensa 
de Caracas, aun cuando reflejan una recepción espléndida de los conciertos, sugieren un esfuerzo notable por parte de sus comentaristas por conciliar las tensiones conceptuales que generaba su ejecución pianística. En virtud de ello, elaboraron alternativas discursivas que daban cuenta del talento de la niña, tratando al mismo tiempo de preservar las convenciones sociales y de género que organizaban la vida musical de Caracas.

\section{Percepciones estéticas}

Las referencias en los comentarios de prensa sobre aspectos específicos de la técnica pianística y el nivel de dificultad de las piezas del repertorio de concierto de Teresa Carreño fueron considerablemente escasas y breves, siendo frecuentemente contrarrestadas por observaciones que enfatizaban, en cambio, la calidad expresiva de su interpretación. Lazarrábal (1862), por ejemplo, afirmaba: "los grandes artistas de Europa hubieran pedido ocho años de estudios para hacer lo que ella hace á los ocho años de vida ... y muchos envidiarían su sensibilidad, su manera propia de expresar, su alma melancólica, su inspiración de fuego" (en Scrapbook I, p. 1). Curiosamente, en otros pasajes de estos mismos artículos se prestaba una gran atención a la apariencia física de la niña. Indudablemente, ello respondía a un intento de resolver en el ámbito corporal la contradicción existente entre su habilidad artística y su corta edad. Resaltan en este sentido las observaciones que hiciera Acosta (1862) sobre el cambio del semblante del Teresa durante su ejecución pianística. Este interpretaba el rostro de la niña como un lugar de inflexión en el que sus modos infantiles daban paso a una retórica visual que daba cuenta de verdadera estatura como artista:

Tantas dotes así no pueden menos que revelarse en su aspecto. En el piano, especialmente improvisando, pierde la fisonomía infantil, de ordinario tan juguetona í graciosa, í asume un aire de majestad indescribible. Allí está su imperio: allí, los secretos que ella sola puede revelar (en Scrapbook I, p. 11).

Más aún, para Acosta (1862) estas variaciones súbitas del semblante de Teresa no se circunscribían a sus momentos como ejecutante, sino que podían ser percibidos también en otras situaciones: "de pié ... su actitud es digna í casi altiva; í pasa de repente del juego á la circunspección, como si pudiese separar del todo dos actos tan opuestos: la niña y el genio" (Acosta, 1862, en Scrapbook I, p. 11). El fragmento sugiere que para Acosta la personalidad de Teresa Carreño como artista constituía una identidad separada de su condición de niña. Esto se advierte aún más claramente cuando Acosta, al caracterizar los rasgos faciales de Teresa, procuraba establecer límites entre una y otra: "sus formas son suaves í hermosas; pero en la cara especialmente, es para notarse el conjunto de curvas ligeramente inclinadas que se cruzan, como para significar así el sexo í el talento" (Acosta, 1862, en Scrapbook I, p. 11). Es significativo que, en esta última descripción, el género femenino de Teresa fuese percibido como una cualidad ostensiblemente separada de su talento. Esta 
disociación entre su condición de género y su identidad artística es finalmente superada mediante un desplazamiento de la causa de su talento a una realidad de orden spiritual. Así pues, Acosta (1862) aseveraba:

Los ojos dan luz inagotable, accesible en sus emanaciones, pero no en su fuente; hai misterio en aquella mirada. ... En fin, el físico presenta una materia iluminada por el alma, í en que tanto se admira el genio como se ama a la mujer (en Scrapbook I, pp. 11-12).

Resulta paradójico que en el escrito de Acosta el cuerpo de Teresa sea representado, no como el centro desde el cual se produce la música, sino más bien como un umbral desde el que es posible divisar un orden ideal distinto de la materia. El cuerpo es construido de este modo como un mapa que indica la existencia de una realidad transcendente; un signo de algo que no se puede apreciar directamente, sino a través de las trazas que Teresa deja al ejecutar el piano, y cuya realidad última no pertenece al mundo físico sino a un plano transcendental. Es posible que se deba precisamente a esta postura el hecho que el entrenamiento musical intensivo que Teresa mantuvo desde temprana edad haya sido completamente opacado en los artículos de prensa publicados en Caracas, en los que se enfatizaba, en cambio, el supuesto origen innato de su talento. En este sentido, Larrazábal señalaba:

sus padres la enseñaron, como el Viejo Mozart al niño de Salzburgo, á encontrar las terceras [...] y, mas después, nada tuvieron que enseñarle. El genio descubria los misterios del arte. Teresita adivinaba, inventaba trazas y modos de llegar á donde debía ir (inquirebat ingeniose); crecia por si misma, y las dificultades de Hummel, de Thalberg, de Mendelssohn quedaron vencidas (Larrazábal, 1862, en Scrapbook I, p. 1).

Era evidente para los comentaristas de Teresa Carreño que las emociones que ella expresaba y transmitía en la música no derivaban de la experiencia, lo cual justificaban alegando que a su corta edad no era posible comprender el mudo de los afectos, ni discernir los matices del espíritu humano. Larrazábal observaba al respecto:

Esas afecciones precoces son un fenómeno de la naturaleza, son un milagro. El niño no está llamado á sentir ni á hacer sentir. ¿Qué descollantes facultades, que fibras tan delicadas y tan flexibles no debemos suponer en la joven de ocho años, que siente como una mujer de treinta? (Larrazábal, 1862, en Scrapbook I, p. 1).

Para Acosta era en el ejercicio de la imaginación donde radicaba la capacidad de Teresa Carreño de tener acceso a una suerte de conocimiento intuitivo e inmediato, el cual le permitía descubrir aquellos sentimientos que expresaba a través de su ejecución y que no podía haber aprendido por medio de la experiencia:

Nosotros sabemos que para las grandes obras se concibe el plan, se ordena, í se le va ejecutando lentamente, frase por frase, dia por dia, año por año; porque el 
ingenio necesita de tiempo para que su fruto nazca, crezca i madure. Pero la primera vez que hemos visto una cosa nacer i perfeccionarse todo á un punto. ... Hacer lo que ella hace, es como hablar en Eneida, ó pintar por juego los frescos del Vaticano (Acosta, 1862,en Scrapbook I, p. 11).

Alternativamente, para Sistiaga (1862) era en la capacidad de Teresa de entregarse a la inspiración artística, de ser movida por algo superior a ella misma, donde se hallaba el origen de su talento artístico: "en aquellos momentos se ve la mano de Dios sobre su cabeza; se ven brotar de sus manos claros destellos de un genio poderoso" (en Scrapbook I, p. 1). Su capacidad expresiva era percibida, por tanto, no como el resultado de su subjetividad, sino como efecto de una realidad transcendente que fluía y se materializaba a través de ella. De manera similar, para Larrazábal (1862) la inspiración de Teresa Carreño la convertía en un recipiente de lo divino:

La lectura de Homero inspiraba á Beethoven: la de Moises á Handel; la poesia de Platon encendia el alma de Mozart y la elevaba á las regiones del infinito; pero ¿quien inspira nuestra Teresa? ¿Quién la inflama? -Ah! Ella podia decirnos como el Dante:

Ecce Deus fortior me [He aquí un Dios más poderoso que yo];

Ó como Ovidio:

Est Deus in nobis [Hay un Dios entre nosotros]

Hai un Dios dentro de mí, que llena mi espiritu de claridades celestes. El me domina: él mueve mis manos: él es quien inspira mis cantos deliciosos, mis acentos de dolor, de pasión y de misterio.

Est Deus in nobis (en Scrapbook I, p. 1).

De modo similar, y estableciendo una relación de intertextualidad con los artículos de Larrazábal y Sistiaga arriba citados, Acosta (1862) se adhería a la interpretación formulada por estos según la cual las habilidades musicales de Teresa Carreño derivaban no de la experiencia sino de una fuerza transcendental que la anima: "el ingenio nace aprendido. La cabeza así es un universo pequeño: no hai edad, no hai tiempo; í sí hai una voz interior que habla, que inspira, que mueve, í que agita. Est Deus in nobis" (en Scrapbook I, p. 10).

\section{Interpretaciones patrióticas}

Larrazábal y Acosta dedicaron una considerable porción de sus artículos periodísticos sobre Teresa Carreño a dilucidar la significación social y cultural su talento musical en el contexto de la coyuntura histórica contemporánea, cuando un sector de 
la intelectualidad venezolana experimentaba una gran aprensión respecto al futuro de la nación. Con el estallido de la Guerra Federal, la violencia remplazaba la racionalidad política y asomaba la posibilidad real del desvanecimiento de los esfuerzos realizados hasta entonces para establecer condiciones de prosperidad y progreso cultural en el país. La capacidad expresiva de Teresa, a la cual se le atribuía un origen divino era interpretada por Larrazábal (1862) como el medio otorgado por la Providencia para aliviar la aflicción y restaurar la cordura perdida tras el desbordamiento de las pasiones: "iQuiera el Cielo que la sublime artista caraqueña pueda siempre cantar penas no sentidas, tormentos y dolores no sufridos; y que ... disipe en magníficos acordes las tempestades del corazón que agitan y menoscaban nuestra mísera existencia" (en Scrapbook I, p. 1). Acosta, en contraposición, interpretaba el momento histórico con inusitado optimismo, argumentando que se trataba de un tránsito doloroso, aunque necesario que daría nacimiento a una nueva época de progreso. Así pues, afirmaba: "las crónicas parciales dirán otra cosa; pero la historia universal ... dirá de ella que sus convulsiones no son sino desenvolvimiento, í que marcha á la civilización" (Acosta, 1862, en Scrapbook I, p. 10). Acosta no tenía dudas de que la contienda bélica en curso en Venezuela se inscribía dentro de un movimiento social y político encauzado a crear un estado de libertad y de orden sin precedentes. Las Américas estaban, según este, llamadas a guiar al mundo civilizado durante esa nueva fase, tanto como Teresa Carreño estaba destinada a representar este cambio histórico por medio del arte musical:

Este estado de cosas debe tener su representante, ó su cronista, ó su grande é inmortal intérprete. Puede ser otro; pero también puede ser María Teresa Carreño [...] ¿Puede haber tanta luz para que no alumbre, tanta fecundidad para que no produzca? Nosotros no creemos eso. Creemos, al contrario, que María Teresa será un ornamento de su patria, í una gloria de su siglo (Acosta, 1862, en Scrapbook I, pp. 12-13).

En la lectura de Acosta se puede discernir la influencia de la filosofía de la llustración, por cuanto este concebía la historia como un récord del progreso humano hacia estados más elevados. Más aún, para Acosta (1862) existía un fin teleológico que, sin importar lo caóticas y devastadoras que pudieran parecer las circunstancias, guiaba el devenir histórico hacía un triunfo inevitable sobre las presentes dificultades:

Es admirable la economía de la Providencia en el desenvolvimiento que va dando, lento pero gradual, á las sociedades humanas, que se mueven adelante sin saber cómo, í se hallan al cabo del tiempo, sin intentarlo, con otros paisajes más hermosos ante la vista, í con cielos cada vez más puros í esplendidos (en Scrapbook I, p. 10).

Para Acosta, los genios ocupan la cúspide del progreso histórico hacia el cual se movía la sociedad en busca de su perfeccionamiento. Estos sirven de heraldos de cada 
nueva fase a alcanzar por la civilización, ya que, a través de su arte y sus conocimientos, logran sintetizar el espíritu de la época que representan:

De ordinario sucede que los genios extraordinarios absorben la época en que viven; así es que para escribir la historia contemporánea, no hai mas que seguir las trazas de ellos ... Tienen tal poder de concentración í atracción, que son como le foco de todos los rayos, í la clave que explica todos los fenómenos actuales (Acosta, 1862, en Scrapbook I, p. 12).

En el marco de una nación sobrepasada por el conflicto social y político, la aparición de una niña con las cualidades artísticas de Teresa Carreño pasó a ser interpretada como el augurio cierto de que la paz y prosperidad que tanto ansiaban los intelectuales caraqueños llegaría finalmente. Para Acosta Teresa era emblema de la esperanza en un futuro promisorio de modernidad y civilidad para Venezuela. Ella se convertía entonces en símbolo de la realización en ciernes de las aspiraciones de progreso social y cultural que habían guiado el establecimiento de las instituciones republicanas, y que continuaba modelando las identidades culturales que se construyeron a lo largo del siglo XIX:

Venezuela no se conoce hoi sino por sus guerras. Pasarán, í de algún dia se hablará de ella como de la Grecia, por el brillo sin la disipación, por el valor sin la barbarie, por los placeres del buen gusto sin la molicie, por la belleza sin la deshonestidad, í por el genio inventor, no el que crea ídolos í dioses, sino el que hace milagros de arte é imitaciones de la creacion que proclaman la gloria de un Dios único (Acosta, 1862, en Scrapbook I, p. 10).

\section{Conclusiones}

Los conciertos privados que Teresa Carreño ofreció en 1862 para un selecto grupo de la élite cultural de Caracas fueron recibidos como eventos de la mayor relevancia artística. Su organización estuvo enmarcada dentro de las convenciones de las reuniones filarmónicas y tertulias poético-musicales, que, desde finales del siglo XVIII, se practicaban en Caracas. Estas estuvieron conformadas por grupos de músicos e intelectuales animados al cultivo serio de la música, la cual percibían como un agente civilizador coadyuvante del progreso cultural. No obstante, la inclusión del repertorio de piezas virtuosas de concierto e improvisaciones en los conciertos de Teresa Carreño en los que ella era la única intérprete representó un elemento de novedad respecto a esta tradición, la cual se había centrado en la ejecución de música instrumental de cámara. La participación de mujeres jóvenes en reuniones de este tipo no era común en Caracas durante esa época, así como tampoco lo fue la esmerada educación musical virtuosística que Teresa Carreño recibió de su padre. El interés y talento musical que demostró desde corta edad operó como elemento de transacción que le confería cierta permisividad en una sociedad que restringía la educación 
de la mujer a la preparación necesaria para desempeñar su rol social esposas y madres, y su actividad musical a la participación en reuniones de salón recreativas donde la música tenía un rol funcional entre otras actividades de sociabilidad y entretenimiento. Tanto por su condición de género como por su corta edad, el avanzado nivel de experticia musical de Teresa Carreño causó gran perplejidad entre los intelectuales que comentaron sus conciertos en la prensa. Estos coincidieron en negar su agencia individual, proponiendo una interpretación según la cual su habilidad era resultado de una fuerza trascendental que actuaba a través de ella y se manifestaba a través de su música. Por otra parte, dado el estado de conmoción social causado por la Guerra Federal en curso, la cual comprometía la racionalidad y la estabilidad del orden republicano, los logros musicales de Teresa Carreño fueron interpretados, con gran optimismo, como signo inequívoco de la capacidad de la nación de avanzar hacia una nueva era de modernidad y logros culturales sin precedentes. La recepción de estos conciertos fue crucial en la construcción de la percepción de Teresa Carreño como uno de los más importantes íconos culturales de Venezuela.

\section{Referencias}

Acosta, C. (Pseud. Amphión). (6 de diciembre de 1862). María Teresa Carreño. El buen sentido. En Scrapbook I [Álbum I] (No. 56, pp. 10-13). Teresa Carreño Papers (Box 11, Folder 1). Archives and Special Collections Library, Vassar College, Poughkeepsie, Nueva York.

Alcibíades, M. (2004). La heroica aventura de construir una república: Familianación en el ochocientos venezolano, 1830-1865. Caracas: Monte Ávila Editores Latinoamericana.

Bello, A., Isasa, J. M., Figueroa, R. y Peña, M. (2001). Proyecto de Sociedad Filarmónica. En J. A. Calcaño, 400 años de música caraqueña (pp. 139-142) (Original publicado en 1831). Caracas: Ediciones de la Biblioteca de la Universidad Central de Venezuela.

Bourdieu, P. (1984). Distinction: A Social Critique of the Judgment of Taste. Cambridge, Mass.: Harvard University Press.

Briceño, M. de. (29 de marzo 1856). Primer concierto de la Sra. Saesmann de Páez. Diario de avisos, y semanario de las provincias, 3.

Brower, H. (1913). Carreño's Technique Parental Gift. Musical America, 19(1), 5.

Campe, J. H. (1840). Eufemia ó La muger verdaderamente instruida: Sacada de la Elisa por el célebre alemán Campe (Original publicado ca. 1806). Barcelona: Miguel y Jaime Gaspar, Padre e Hijo.

ESCENA. Revista de las artes, 2020, Vol. 79, Núm. 2 (enero-junio), pp. 148-173 
Los conciertos de Teresa Carreño en Caracas en 1862: construcciones

Dossier

de género, virtuosismo y patriotismo

Carreño, M. A. (1863) Manual de urbanidad y buenas maneras para uso de la juventud de ambos sexos (Original publicado en 1853). Nueva York: D. Appleton y Compañía.

Carreño, M. A. (ca. 1859-1869). Various studies in piano technique [Varios estudios en técnica pianística]. Teresa Carreño Papers (Box 3, Folder 13). Archives and Special Collections Library, Vassar College, Poughkeepsie, Nueva York.

Carreño, T. (28 de junio de 1917). Teresa Carreño's Reminiscences. W. Armstrong (Ed.). Musical Courier, 6-7.

Carreño, T. (2008). Obras para piano. J. F. Sanz y L. Pita (Eds.). Caracas: Universidad Central de Venezuela.

Cartas sobre la educación del bello sexo por una señora americana. (1824). Londres: R. Ackermann.

Castillo Didier, M. (1993). Cayetano Carreño: Ensayo de esbozo biográfico. Caracas: Biblioteca Ayacucho.

Composiciones de María Teresa Carreño. (1860-1861). Teresa Carreño Papers (Box 2, Folder 9). Archives and Special Collections Library, Vassar College, Poughkeepsie, Nueva York.

Dahlhaus, C. (1989). Nineteenth-Century Music. Berkeley: University of California Press.

De la Plaza, R. (1977). Ensayos sobre el arte en Venezuela (Original publicado en 1883). Caracas: Ediciones de la Presidencia de la República; Imprenta Nacional, 1977.

Fabronius, D. C. (1863). Teresa Carreño, The Child Pianist [litografía]. Boston: A. Trochsler. Recuperado de http://loc.gov/pictures/resource/pga.10539/

Ferris, D. (2003). Public Performance and Private Understanding: Clara Wieck's Concerts in Berlin. Journal of American Musicological Society, 56(2), 352-408.

Gasparini, G. (1962). La casa colonial venezolana. Caracas: Universidad Centra de Venezuela.

Iriarte, T. de. (1779) La música, Poema. Madrid: Imprenta Real de la Gazeta.

Isnardi, F. (enero de 1811). Variedades: Literatura y bellas artes. Mercurio venezolano, (1), 53-60.

Lajolais, N. de. (1843). Le Livre des mères de famille et des institutrices sur l'éducation practique des femmes. (2a ed.). París: Didier.

Larrazábal, F. (27 de mayo de 1862). Tributo de justicia al mérito. El independiente. En Scrapbook I [Álbum I] (No. 1, p. 1). Teresa Carreño Papers (Box 11, Folder 1). Archives and Special Collections Library, Vassar College, Poughkeepsie, Nueva York.

ESCENA. Revista de las artes, 2020, Vol. 79, Núm. 2 (enero-junio), pp. 148-173 
Leppert, R. (2002). Cultural Contradiction, Idolatry, and the Piano Virtuoso: Franz Liszt. En J. Parakilas (Ed.), Piano Roles: A New History of the Piano (pp. 200-223). New Haven, Conn.: Yale Nota Bene.

Lii, D.T. (1998). Social Spheres and Public Life: A Structural Origin. Theory, Culture and Society, 15(2), 115-135.

Macintyre, I. (2010). Women and Print Culture in Post-Independence Buenos Aires. Woodbridge, Suffolk, Gran Bretaña: Tamesis.

Milanca, M. (2000). Los salones: Primeros escenarios de Teresa Carreño. En J. Peñín (Ed.), Música iberoamericana de salón: Actas del Congreso Iberoamericano de Musicología (pp. 573-608). Caracas: Fundación Vicente Emilio Sojo.

Milinowski, M. (1940). Teresa Carreño: By the Grace of God. New Haven, Conn.: Yale University Press.

Parakilas, J. (Ed.). (2002). Piano Roles: A New History of the Piano. New Haven, Conn.: Yale Nota Bene.

Pita, L. (2019) Teresa Carreño's Early Years in Caracas: Cultural Intersections of Piano Virtuosity, Gender, and Nation-Building in the Nineteenth Century (tesis doctoral). University of Kentucky, Lexington, Kentucky. Recuperado de https://uknowledge. uky.edu/music_etds/134/

Quintana, H. (2009). Textos y ensayos musicales pertenecientes a la biblioteca de la Universidad de Caracas (Período colonial). Caracas: Universidad Central de Venezuela.

Rodríguez, F. (1999). Caracas, La vida musical y sus sonidos: 1830-1888. Caracas: Contraloría general de la República, Fondo Editorial 60 Años.

Sans, J. F. (2016). Los bailes de salón en Venezuela. Caracas: Fundación Bigott.

Scrapbook I [Álbum I] (Mayo 1862-Junio 1868). Teresa Carreño Papers (Box 11, Folder 1). Archives and Special Collections Library, Vassar College, Poughkeepsie, Nueva York.

Sistiaga, J. M. (15 de julio de 1862). Orgullo nacional. El independiente. En Scrapbook I [Älbum I] (No. 2, p. 1-2). Teresa Carreño Papers (Box 11, Folder 1). Archives and Special Collections Library, Vassar College, Poughkeepsie, Nueva York.

Suárez, J. M. (1999). Compendio de historia musical desde la Antigüedad hasta nuestros días (Original publicado en 1909). Revista musical de Venezuela, (39), 269-373. 